\title{
Sizing, design, and modelling of aerospace electric drive system with long feeder cables
}

\author{
Patrick Xie ${ }^{1}$, Gaurang Vakil, Chris Gerada \\ Power Electronics, Machine and Control Group \\ University of Nottingham \\ Nottingham, UK \\ eexpx1@nottingham.ac.uk ${ }^{1}$
}

\begin{abstract}
The aviation industry is tending towards more electric aircraft, replacing conventionally pneumatic, hydraulic, and mechanical systems with electrical solutions. The electrification of actuators is motivated by increased efficiency, reduced maintenance and potential mass savings. Special considerations need to be made when designing an aerospace application electric drive system with long feeder cables. For a given actuation requirement, mass and volume need to be minimized while obeying thermal and reliability constraints. Fast switched high dV/dt voltages applied to a cable with poor machine-cable impedance matching can cause high-amplitude high-frequency voltage oscillations, potentially leading to corona discharge, insulation failure, high common-mode, differential-mode currents, bearing currents, and reduced lifetime of system. Mitigation of these voltage oscillations can reduce and/or eliminate the problems associated with it. In this paper, the details of a high-level electric drive system design tool for component sizing and modelling is described. The designed systems mass, volume, thermals, reliability and performance figures are produced. To demonstrate the design tool, the results of a hypothetical $3 \mathrm{~kW}$ centralized electric drive system case study is presented. A LC inverter filter is used to mitigate long feeder cables.

Index Terms-Sizing, system analysis, system design, aerospace, electric drive, more electric aircraft, long-feeder cable.
\end{abstract}

\section{INTRODUCTION}

The motivation for more electric aircraft (MEA) is to improve performance and serviceability while reducing maintenance costs, and mass. The MEA concept involves the replacement of conventional pneumatic, hydraulic, and mechanical systems with electrical systems. The objective of aerospace electric drive system design is to minimise the systems mass and volume for a given actuation requirement while respecting the thermal, electrical, efficiency, and power quality limits of the system and its components. Sizing and design of an aerospace electric drive system with long feeder cables is a multi-variable, multi-domain optimisation problem with multiple constraints. Thermal, electrical, mechanical, reliability, and efficiency are all interconnected and must all be considered simultaneously during the design phase.

Topology and application specific design challenges and constraints need to be considered for electric drive system design and sizing for aerospace applications. Here, a centralised electric drive system is presented where the machine driving the actuator and inverter are separated by a long feeder cable. The machine and the feeder cable are in an unpressurised environment in the wing while the inverter is in the fuselage. This topology is advantageous where the inverter is operating in a more hospitable environment with easily accessibility to coolant compared to the machine and the feeder cable. High-altitude low-pressure atmosphere reduces the cooling capacity of both natural and forced convection air cooling. All components in the wing are naturally air-cooled and do not have access to liquid cooling due to added weight of coolant routing. This reduces the power density of components.

High altitude, low pressure environment reduces the corona discharge voltage. Special care needs to be applied to the insulation coordination of all components operating in lowpressure environment. Excessive corona discharge causes deterioration of insulation, ultimately leading to short-circuiting and failure of the drive.

Fast switched voltages with high dv/dt applied to cables whose surge impedance is poorly matched with that of the machine causes high-amplitude high-frequency voltage oscillations throughout the cable, at the machines terminals, and throughout the machines windings due to transmission line effects. The machine side voltage can be up to twice the DCbus voltage and sometimes three times the DC bus voltage if voltage pulses are applied before oscillations sufficiently decay [1]. This can cause corona discharge, ultimately leading to insulation failure and drive failure. High common-mode voltage can cause common-mode current and bearing currents, which can lead to premature failure of the bearing [2]. Oscillatory voltages, CM currents, and DM currents can cause excess unwanted EMI.

In this paper, sizing and design methods for an aerospace electric drive system are presented. The level of detail of these sizing methods is at the boundary between system level and component level design. The described application specific and operating environment specific design challenges are addressed. The sizing and design procedure is applied to a $3 \mathrm{~kW}$ centralised electric drive system case study. The components considered for sizing are the inverter, LC filter, long feeder cable, and machine.

\section{TOPOLOGY}

The topology considered is shown in Fig. 1. A centralised layout is shown where the machine is located externally 


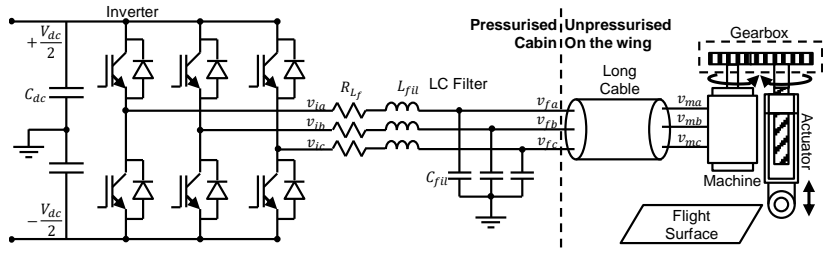

Fig. 1. Electric drive with LC output filter, diode bridge voltage clamp and snubber circuit.

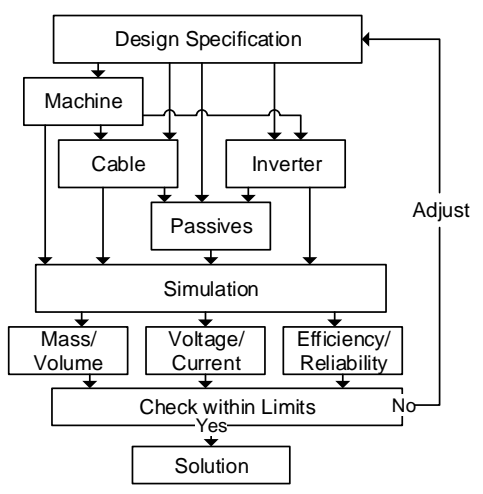

Fig. 2. System sizing flow chart.

on the wing driving an actuator and connected to the infuselage inverter and filter via a long feeder cable. The inverter generates switched voltages and the LC filter reduces the rise time of switched voltages applied to the inverter side of the long feeder cable. This in turn reduces the voltage overshoot on the cables load side.

\section{System Sizing And Design Procedure}

A flow chart of the system sizing is shown in Fig. 2. The components considered in the electric drive system are the machine, cable, inductor, capacitor, and inverter. The machine is sized based on torque/speed requirements, duty cycle, dc link voltage, switching frequency, desired current ripple, maximum internal temperature, and ambient temperature. From there, the current demand for both nominal and peak operating current is calculated. The cables conductor and inverter can be sized for the current ratings. The cables insulation is sized based on operating voltage and altitude. Once the cable is fully dimensioned, the passive filters can be sized to deal with the transmission line effects of the long feeder cables. Once all components are sized can a full system simulation be built. Electrical, thermal, electromechanical, reliability, and efficiency parameters can be calculated. These results are checked if they are within design limits and have met design requirements. If not, design specifications and inputs are adjusted until the criteria are met.

\section{A. Machine}

For machine sizing, a three-phase surface mounted permanent magnet synchronous machine is considered because of its high-power density and low rotor losses. The machine optimisation problem defined by the design procedure has been solved by simple iteration of design inputs within a user defined search space and resolution. The machine design sizing procedure steps are as follows.

1) Specification input: The machine's desired performance specifications, operating environment, material's data, and basic machine parameters, geometries and aspect ratios are set.

2) Rotor and stator sizing: The general machine geometry is determined using fundamental machine sizing equations provided by [3]. The electric loading $A$, defined as the average current density around the air gap circumference, is as follows,

$$
A=\frac{2 m N_{p h} I_{p h}}{\pi D},
$$

where $m$ is the number of phases, $N_{p h}$ is the turns per phase, $I_{p h}$ is the phase current, and $D$ is the rotor diameter. The magnetic loading $B$, defined as the average flux density around the air gap, is,

$$
B=\frac{2 p \phi_{1}}{\pi D L_{s t k}},
$$

where $p$ is the number of pole pairs, $\phi_{1}$ is the fundamental component of the flux linkage, and $L_{s t k}$ is the stack length. The generated back EMF per phase $E$ is expressed as follows,

$$
E=\frac{2 \pi}{\sqrt{2}} k_{w 1} N_{p h} \phi_{1} f
$$

where $k_{w 1}$ is the fundamental harmonic winding factor, typically between 0.85 and 0.95 and $f$ is the electrical frequency. The relationship between the torque per rotor volume (TRV), the magnetic loading $B$ and the electric loading $A$ is as follows,

$$
\mathrm{TRV}=\frac{T}{V_{r}}=\frac{\pi}{\sqrt{2}} k_{w 1} A B
$$

The current density $J$ is expressed as follows,

$$
J=\frac{A}{F_{\text {slot }} d(1-\tau)},
$$

where $F_{\text {slot }}$ is the slot-fill factor, $d$ is the slot depth, and $\tau$ as the ratio of the slot tooth width to slot pitch.

For a given value of TRV and $L_{s t k}=x D_{r}$, rotor volume $V_{r}$, rotor diameter $D_{r}$, and stack length $L_{s t k}$ are calculated. The average magnetic loading $B$ is related to the peak tooth magnetic flux $B_{t(p k)}$ as shown,

$$
B=2 \tau B_{t(p k)} / \pi .
$$

Typical values of $\tau$ and $B_{t(p k)}$ are 0.5 and 1.6T respectively. The magnetic loading $A$ is calculated using (4) and number of turns per phase $N_{p h}$ can be solved from (1),

$$
N_{p h}=\frac{A \pi D_{r}}{2 m I_{p h}} .
$$

Knowing current loading $A, d$ can be calculated from (5) for a given $J$ and $F_{\text {slot }}$. Typical value for $F_{\text {slot }}$ is 0.4 . The back-iron depth $d_{b k}$ as follow,

$$
d_{b k}=\frac{N_{s l} m}{N_{p}} t_{w} .
$$




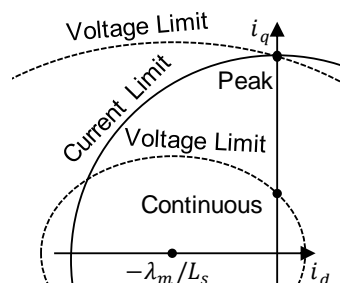

Fig. 3. Continuous and peak operating points on the dq-current plot.

3) Winding sizing: The machine windings' length are dimensioned considering full-pitch or pitch-shortened windings, and number of conductors. A semi-circle path is assumed for the end-winding [4]. The conductor's cross sectional area is calculated from the available slot space and slot fill factor.The per-phase stator resistance can be determined from the conductor's cross sectional area and length.

4) Stator inductance and magnet flux linkage: The stator inductance $L_{s}$ and magnet flux linkage $\lambda_{m}$ are determined using the machine's voltage equations and torque equation in the dq synchronous reference frame as shown,

$$
\begin{gathered}
v_{d}=R_{s} i_{d}+L_{s} \frac{d i_{d}}{d t}-\omega_{e} L_{s} i_{q} \\
v_{d}=R_{s} i_{q}+L_{s} \frac{d i_{q}}{d t}+\omega_{e} L_{s} i_{d}+\omega_{e} \lambda_{m}, \\
T=\frac{3 p}{2} \lambda_{m} i_{q}
\end{gathered}
$$

where $\omega_{e}$ is the electrical frequency.

Expressions for the voltage limit $V_{\max }$ and current limit $I_{\max }$ are as follows,

$$
\begin{gathered}
V_{\max }=\frac{V_{d c}}{\sqrt{3}} \geq \sqrt{v_{d}^{2}+v_{q}^{2}}, \\
I_{\max }=\frac{2 T_{p k}}{3 p \lambda_{m}} \geq \sqrt{i_{d}^{2}+i_{q}^{2}},
\end{gathered}
$$

where $V_{d c}$ is the DC link voltage and $T_{p k}$ is the peak torque.

The relationship between peak-to-peak current ripple to peak-to-peak phase current ratio $c$ and $L_{s}$ is as follows,

$$
L_{s}=\frac{V_{d c}}{\sqrt{2} \pi^{2} c i_{q} f_{s w}}
$$

where $f_{s w}$ is the inverter switching frequency.

Equation (11) is solved for $\lambda_{m}$ to give the following expression,

$$
\lambda_{m}=\frac{2 T_{e m}}{3 p i_{q}} .
$$

Consider the continuous and peak operating points in the $\mathrm{dq}$ current plane as shown in Fig. 3 with no field weakening such that $i_{d}=0$. Equations (14) and (15) are substituted into the dq voltage equations (9)-(10) and then into voltage limit equation (12) to give an expression of voltage limit with respect to $i_{q}$,

$$
\left|v_{d q}\right|=\sqrt{\left(-\omega_{e} \frac{V_{d c} T_{s w}}{\pi^{2} c i_{q}}\right)^{2}+\left(R_{s} i_{q}+\omega_{e} \frac{2 T_{e m}}{3 p i_{q}}\right)^{2}} .
$$

For an array of values of operating current $I_{p h}$, corresponding values of $R_{s},\left|v_{d q}\right|, L_{s}$, and $\lambda_{m}$ can be calculate at nominal operating electrical angular speed $\omega_{e}$ using a script consisting of steps 1-4. Feasible values of $L_{s}, \lambda_{m}$ and candidate machine designs for the next step correspond to value design's whose values of $\left|v_{d q}\right| \leq V_{\max }$.

5) Air gap and magnet sizing: The air gap and magnet thickness are determined for the calculated stator inductance and magnet flux linkage from step 4. The stator inductance for a three-phase SPMSM, machine is as follows [5],

$$
\begin{gathered}
L_{s}=\frac{6}{\pi} \frac{\mu_{0} N_{p h}^{2} k_{w 1}^{2} L_{s t k} r_{r a}}{p^{2} g_{2}}, \\
g_{2}=K_{c} d_{a}+d_{m} / \mu_{r e c}
\end{gathered}
$$

and $K_{c}$ is the Carter's coefficient approximated as follows [5],

$$
K_{c}=\frac{5+w_{s s} / d_{a}}{5+w_{s s} / d_{a}-\left(w_{s s} / d_{a}\right)^{2}\left(d_{a} / \lambda\right)},
$$

where $w_{s s}$ is the slot opening at the stator bore, $d_{a}$ is the air gap and $\lambda$ is the tooth pitch. The magnet's operating point is determined using an equivalent magnetic circuit [6] for given magnet operating temperature.

6) Mass, volume, losses, efficiency, power factor: Mass and volume calculations are trivial given the full geometry of the machine and respective component densities. Copper losses is calculated are as follows,

$$
P_{c u}=3 I_{p h}^{2} R_{s}
$$

The per volume core losses can be determined using iGSE [7]. Power factor for the nominal and peak operating point are calculated from their respective operating dq voltage and currents,

$$
P F=\cos \left(\arctan \left(v_{q} / v_{d}\right)-\arctan \left(i_{q} / i_{d}\right)\right) .
$$

7) Thermal analysis: a lumped parameter thermal network from [8] is considered for thermal analysis. Each component of the machine's geometry is modelled as a cylinder whereby axial and radial heat flows are independent of each other. To ensure accurate transient and steady state temperature calculations, the frame to ambient thermal resistance as a function of frame and ambient temperature needs to be determined [9] [10].

\section{B. Inductor}

Inductors are sized assuming an EI core where the ratio of its geometry are fixed [11]. The inputs for inductor sizing are required inductance, its steady state current waveform, fundamental frequency, current density, initial estimate of core flux density, maximum rise time, ambient temperature, and core materials Steinmetz properties. Given the operating current $I_{r m s}$, desired inductance $L$, and fundamental frequency $f$, current density $J$, the RMS voltage $V_{L}$ and apparent power $V A$ are calculated as follows,

$$
V_{L}=2 \pi f L I_{r m s}
$$




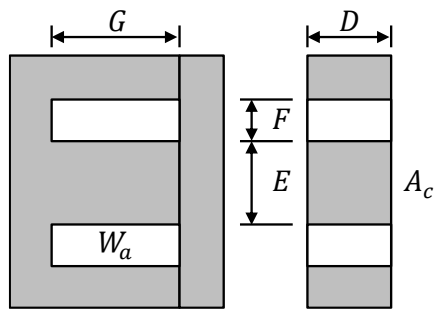

Fig. 4. EI core dimensions [11].

$$
V A=V_{L} I_{r m s} .
$$

The area product $A_{p}$ is calculated as,

$$
A_{p}=\frac{V A}{K_{f} K_{u} B_{a c} J}
$$

where the window fill factor $K_{u}$ is assumed to be 0.4 , and the waveform factor $K_{f}$ is 4.44 for a sine-wave.

The EI core dimensions shown in Fig. 4 are calculated as follows, assuming a ratio for $W_{a} / A_{c}$ is 0.8 and $G / F$ is 3 .

$$
\begin{gathered}
A_{c}=\sqrt{A_{p} /\left(W_{a} / A_{c}\right)} \\
D=E=\sqrt{A_{c}} \\
F=\sqrt{W_{a} /(G / F) .}
\end{gathered}
$$

The total number of turns $N_{L}$ is calculated as,

$$
N_{L}=\frac{V_{L}}{K_{f} B_{a c} A_{c}},
$$

and gap length is calculated as,

$$
l_{g}=\frac{0.4 \pi N_{L}^{2} A_{c}}{L}-\frac{\mathrm{MPL}}{\mu_{m}},
$$

where $\mu_{m}$ is the core material's magnetic permeability, and MPL is the mean magnetic path length,

$$
\mathrm{MPL}=2(E+G+F) .
$$

The mean length per turn (MLT) and the bare wire are calculated determined as follows,

$$
\begin{gathered}
\mathrm{MLT}=4(D+F) . \\
A_{w L B}=I_{r m s} / J .
\end{gathered}
$$

The series resistance is calculated knowing MLT, turns number and bare wire area,

$$
R_{L}=\frac{\rho_{c u} N_{p h} \times \mathrm{MLT}}{A_{w L B}} .
$$

where $\rho_{c u}$ is the resistivity of copper. The winding copper power loss is calculated as,

$$
P_{c u}=I_{r m s}^{2} R_{c} .
$$

Core loss is calculated using iGSE [7]. The total power loss $P_{\text {sum }}$ is the sum of the winding copper loss and the core loss.
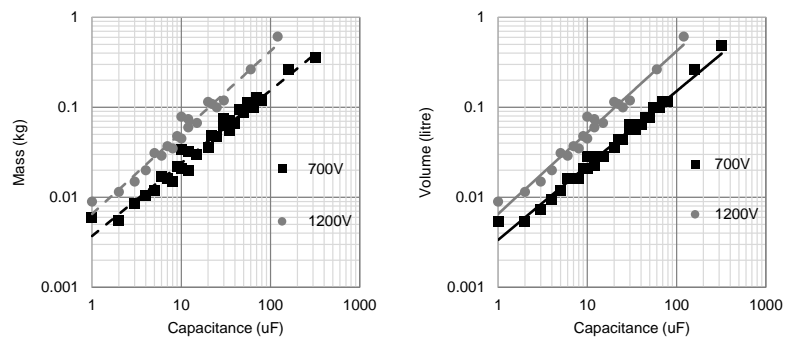

Fig. 5. Capacitor mass and volume vs. capacitance [13].

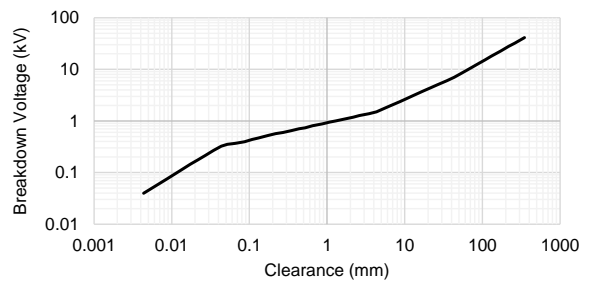

Fig. 6. Breakdown voltage vs. clearance at 40,000ft.

A lumped parameter thermal model is used where the equation for the inductors temperature-rise $T_{r(n a t)}$ for natural convection calculation in an enclosed box for a given ambient atmospheric pressure and hydraulic length $L_{h}$ is provided by [12],

$$
T_{r(\text { nat })}=\left(\left(\frac{\theta_{a}}{\theta_{\text {ref }}}\right)^{8.72} L_{h}^{11.4} \frac{P_{\text {sum }}^{40}}{C^{40}\left(\frac{P_{a}}{P_{\text {ref }}}\right)^{19.08}\left(A_{t}\right)^{40}}\right)^{1 / 49}
$$

where $C$ is the coefficient of inductor orientation and assumed to be 1.35 for an enclosed inductor, $\theta$ is the temperature in Kelvin, $P$ is the pressure, and subscripts " $a$ " and "ref" represent ambient and reference (standard temperature and pressure) values.

\section{Capacitor}

Capacitor sizing is done empirically by fitting a mass and volume vs. capacitance curve for a given voltage rating using data sheet values from [13] as shown in Fig. 5. A power curve is used to fit the mass vs. capacitance and mass vs. volume.

\section{Cable}

The cable's conductors and insulation are sized for current carrying capability, safe operating voltage, and operating environment. Reference [14] provides conductor sizing tables based on load current, bundle number derating factor, and altitude derating factor. Increased conductor bundle no. and operating altitude reduces current rating.

The corona discharge breakdown voltage reduces with increase in altitude and reduction in pressure. Cable's insulation coordination is completed following [15]. It provides values for breakdown voltage for clearance distances and altitude correction factors, as shown in Fig. 6 for an altitude of $40,000 \mathrm{ft}$. 


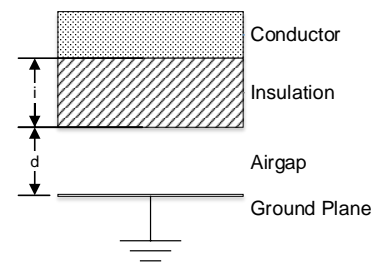

Fig. 7. Insulation coordination safe operating voltage.

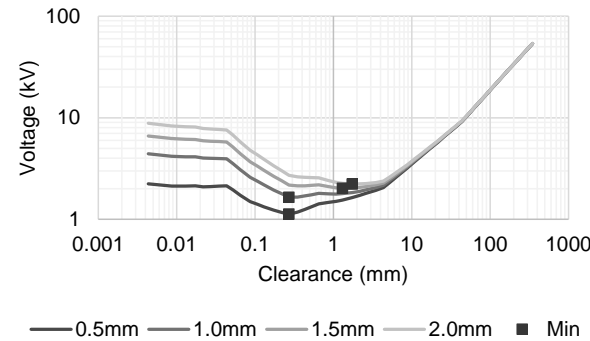

Fig. 8. Safe operating voltage vs. clearance distance for insulation thickness's $0.5 \mathrm{~mm}-2.0 \mathrm{~mm}$.

The basic insulation thickness is sized for rated altitude considering the minimum safe operating voltage (SOV) between two wires or between a wire and ground plane for any given air gap separation distance as shown in Fig. 7. The total fraction of the wire voltage (between conductor and ground plane) that is a cross the air gap $V_{d}$ is,

$$
V_{d}=\frac{d}{d+i / \epsilon_{r}},
$$

where $d$ is the air gap, $i$ is the basic insulation thickness, and $\epsilon_{r}$ is relative permittivity of the insulation.

To calculate the SOV of the wire with respect to ground, the breakdown voltage of each clearance air gap $d$ is divided by $V_{d}$ for all clearance values provided by Fig. 6 . The results of this are plotted in Fig. 8 for basic insulation thickness's of $0.5-2.0 \mathrm{~mm}$. The SOV is the minimum voltage for a given insulation thickness as marked by the black squares. The SOV vs. insulation thickness are plotted in Fig. 9.

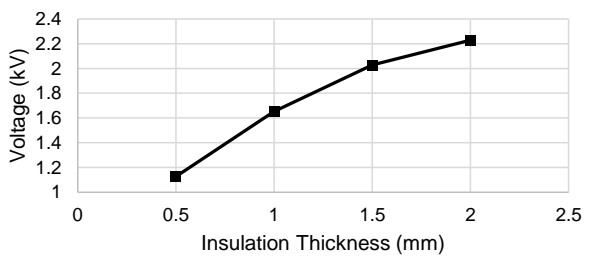

Fig. 9. Safe operating voltage vs. insulation thickness.

The maximum potential electric field strength the insulation can withstand is when air gap between two wires or wire to ground plane is zero. This condition is used to check if the limits of the maximum potential electric field strength of the insulation. Finally, the layers of basic insulation is doubled for redundancy.
Cables per unit length line (PUL) resistance, line inductance, phase-to-phase capacitance and phase-to-ground capacitance is calculated from [16] and [17],

$$
\begin{gathered}
R_{d c}^{\prime}=\frac{\rho_{c u}}{\pi r_{1}^{2}}, \\
R_{a c(l f)}^{\prime}=\frac{\rho_{c u}}{\pi\left(r^{2}-\left(r_{1}-\frac{1}{\sqrt{\pi \mu_{0} \sigma_{c u}}}\right)^{2}\right)}, \\
L^{\prime}=\frac{\mu_{0}}{\pi} \ln \left(\frac{D}{r_{1}}\right), \\
L_{m}^{\prime}=\frac{\mu_{0}}{2 \pi} \ln \left(\frac{r_{0}^{2}}{r_{1} D}\right), \\
C_{p}^{\prime}=\frac{2 \pi \epsilon}{\ln \left(16 r_{0}\left(\frac{\left.b_{r}^{6} / r_{0}^{3}\right)-r_{0}^{3}}{3\left(2 b_{r}\right)^{3} 2 r_{1}}\right)\right)}, \\
\frac{1}{\mu \epsilon}\left(\left(\frac{\mu_{0}}{2 \pi} \ln \left(\frac{D^{2}}{r_{1}^{2}}\right)\right.\right. \\
\left.\left.\ln \left(\frac{4 b_{r}^{2}}{r_{1}^{2}}\right)\right)^{2}-\left(\frac{\mu_{0}}{2 \pi} \ln \left(\frac{2 b_{r}}{r_{1}}\right)\right)^{2}\right)
\end{gathered}
$$

where $R_{d c}^{\prime}$ and $R_{a c(l f)}^{\prime}$ are the DC resistance and resistance at fundamental frequency $f$ due to skin effect, $L^{\prime}$ and $L_{m}^{\prime}$ are the self- and mutual-inductance, $C_{g}^{\prime}$ and $C_{p}^{\prime}$ are the phase to ground and phase to phase capacitances, $\rho_{c u}$ is the resistivity of copper, $\mu_{0}$ is permittivity of free space, $\sigma_{c u}$ is the conductivity of the copper, $b_{r}$ is the bundle radius, $r_{1}$ is the radius of the conductor, $r_{0}$ is the distance from centre of conductor to centre of bundle, $D$ is the pitch distance between the conductors, and $\epsilon$ is the permittivity of the insulation.

High-frequency high-amplitude voltage oscillations due to transmission line effects are simulated using a linear distributed parameter transmission line model based on the telegrapher's equation.

\section{E. Inverter}

A two-level six-switch IGBT inverter is considered. Inverter power modules are selected from a database. The IGBTs and diodes conduction and switching power losses are determined assuming space vector modulation using [18] as follows,

$$
\begin{gathered}
P_{\operatorname{cond}(T)}=\left(\frac{1}{2 \pi}+\frac{m \cos (\phi)}{8}\right) V_{C E 0}\left(T_{j}\right) \hat{I}_{1}+\ldots \\
\left(\frac{1}{8}+\frac{m \cos (\phi)}{3 \pi}\right) r_{C E}\left(T_{j}\right) \hat{I}_{1}^{2} \\
P_{s w(T)}=f_{s w} E_{\text {on }+ \text { off }} \frac{\sqrt{2}}{\pi} \frac{I_{\text {out }}}{I_{r e f}} \times \ldots \\
\frac{V_{c c}}{V_{r e f}}\left(1+\mathrm{TC}_{E_{s w}}\left(T_{j}-T_{r e f}\right)\right), \\
P_{t o t(T)}=6\left(P_{\operatorname{cond}(T)}+P_{s w(T)}\right) .
\end{gathered}
$$

The subscript "sw" and "cond" refer to switching and conduction losses, $m$ is the modulation index, $\phi$ is the phase lag, $V_{C E 0}\left(T_{j}\right)$ is the threshold voltage of the on-state characteristics as a function of junction temperature $T_{j}, \hat{I}_{1}$ is the peak 


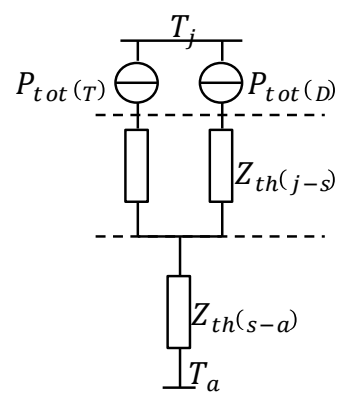

Fig. 10. Inverter thermal network.

operating current equal to $\sqrt{2} I_{p h}, r_{C E}$ is the bulk resistance of the on-state characteristics, subscript "ref" are data sheet reference values for current, voltage, and temperature, $K_{v}$ is the voltage dependency exponent of switching losses equal to $1.35, \mathrm{TC}_{E s w}$ is the temperature switching coefficient, $\approx 0.003$ $1 / \mathrm{K}$.

The diode conduction and switching losses equations are as follows,

$$
\begin{gathered}
P_{\text {cond }(D)}=\left(\frac{1}{2 \pi}-\frac{m \cos (\phi)}{8}\right) V_{F 0}\left(T_{j}\right) \hat{I}_{1}+\ldots \\
\left(\frac{1}{8}-\frac{m \cos (\phi)}{3 \pi}\right) r_{F}\left(T_{j}\right) \hat{I}_{1}^{2}, \\
P_{s w(D)}=f_{s w} E_{r r} \frac{\sqrt{2}}{\pi}\left(\frac{I_{1}}{I_{r e f}}\right)^{K_{i}} \times \ldots \\
\left(\frac{V_{c c}}{V_{r e f}}\right)^{K_{v}}\left(1+\mathrm{TC}_{E r r}\left(T_{j}-T_{r e f}\right),\right. \\
P_{t o t(D)}=6\left(P_{\operatorname{cond}(D)}+P_{s w(D)}\right) .
\end{gathered}
$$

where $V_{F 0}$ is the on-state threshold voltage as a function of $T_{j}$, $r_{F}$ is the on-state bulk resistance, $K_{V}$ and $K_{i}$ are the voltage and current dependency of switching losses, both $\approx 0.6$, and $\mathrm{TC}_{E r r}$ is the temperature coefficients of the switching losses.

A thermal network is used to represent the junction to case, case to heatsink and heat sink to ambient thermal resistances as shown in Fig. 10. From here, the required heat sink to ambient thermal resistance is determined and an appropriate cooling solution can be sized. Liquid-cooling is typically used on aerospace for power inverters [19] as it takes up less space, weighs less compared to conventional parallel plate fin air heat sink cooler, and has many magnitudes higher cooling capability.

\section{LC FILTER PARAMETER SELECTION}

Steep-fronted switched voltages with high $\mathrm{dv} / \mathrm{dt}$ applied to long feeder cables whose surge impedance matches poorly with that of the load side can cause high-frequency, highamplitude voltage oscillations due to transmission line effects throughout the cable and at the machine's terminals. To address the ill-effects caused by steep-fronted switched voltages, an LC filter between the inverter and the cable is proposed to reduce the effective applied voltage's dv/dt. The cut-off frequency of the filter $f_{\text {fil }}$ is selected as,

$$
f_{\text {fil }}=\frac{f_{\text {h_att }}}{10^{\frac{A_{\text {req_att }}}{\text { fil_att }}}},
$$

where $f_{\mathrm{h} \_ \text {att }}$ is the frequency of a specific harmonic $\mathrm{h} \_$att to be attenuated by an amount $A_{\text {req_att }}$ in decibels and fil_att is the filter's intrinsic attenuation. Here, the LC filter's intrinsic attenuation is $-40 \mathrm{~dB} /$ decade and $\mathrm{h}$ _att is set equal to the inverter switching frequency. The cut-off frequency of the filter is selected to be between the fundamental electrical frequency of the machine and below the switching frequency of the inverter.

The filter inductance $L_{f i l}$ is determined as follows for a desired capacitor peak-to-peak ripple current to peak-to-peak inductor current ratio $c_{C}$ and inductor current $I_{L}$,

$$
L_{f i l}=\frac{V_{d c}}{\sqrt{2 \pi^{2} c_{C} I_{L} f_{s w}}} .
$$

The filter capacitance $C_{f}$ is determined from $L_{f}$ and $f_{\text {fil }}$,

$$
\begin{gathered}
C_{f i l}=\frac{1}{\left(2 \pi f_{\text {fil }}\right)^{2} L_{f i l}} . \\
\text { V. RELIABILITy }
\end{gathered}
$$

The failure rate of the switches, diodes, inductor, capacitor are determined using FIDES reliability models [20]. The FIDES general reliability model expresses a part's reliability $\lambda$ as a function of the physical contribution $\lambda_{\text {Physical }}$, the parts quality and manufacturing control $\Pi_{\mathrm{PM}}$, and manufacturing process $\Pi_{\text {Process }}$ as shown,

$$
\lambda=\lambda_{\text {Physical }} \Pi_{\mathrm{PM}} \Pi_{\text {Process }}
$$

The physical contribution $\lambda_{\text {Physical }}$ is a function of the base failure rate, acceleration factor and induced factors as shown,

$$
\lambda_{\text {Physical }}=\Sigma_{\text {Physical-contributions }}\left(\lambda_{0} \Pi_{\text {acceleration }}\right) \Pi_{\text {induced }}
$$

Aerospace application specific lifetime profiles are provided by [20] and describes the operation of a year.

Failure rate equations vary from component to component. The general expression to determine physical contribution for a given application/environment life profile is as follows,

$$
\begin{gathered}
\lambda_{\text {Physical }}=\lambda_{0} \Sigma_{i}^{\text {Phases }}\left(( \frac { t _ { \text { annual } } } { 8 7 6 0 } ) \left(\Pi_{\text {Thermo-electrical }}+\ldots\right.\right. \\
\left.\left.\Pi_{\mathrm{TCy}}+\Pi_{\text {mechanical }}\right) \times\left(\Pi_{\text {Induced }}\right)_{i}\right) .
\end{gathered}
$$

The switches', diodes', inductors' and capacitors' failure rates have been calculated using FIDES guide. Reliability values for the insulation, bearings, control signals, power supply, actuator mechanism and gearbox have been taken from literature [21].

Fault tree analysis is used to determine the failure rate for a single lane of this system in units of failures per hour. For this system, the failure rate is determined at $1.4 \times 10^{-5}$ failures per hour as seen in Fig. 11 while the desired failure rate for flight-critical systems is $1 \times 10^{-10}$ failures per hour. A single 


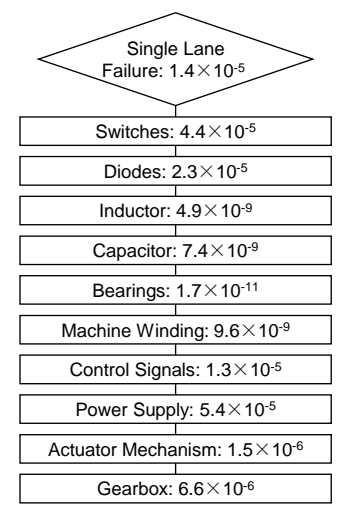

Fig. 11. Fault tree analysis for single-lane configuration.

TABLE I

COMPARISON OF PHASE CONFIGURATION AND SIZE FACTORS OF MULTI-LANE THREE-PHASE FAULT-TOLERANT TOPOLOGIES [21].

\begin{tabular}{lcccc}
\hline Phase configuration & 3 & $3+3$ & $2 \times 3+3$ & $3 \times 3+3$ \\
\hline \hline Functional lanes post fault & 0 & 1 & 2 & 3 \\
Machine phases & 3 & 6 & 9 & 12 \\
Switches & 6 & 12 & 18 & 24 \\
Isolated gate drives & 3 & 8 & 12 & 16 \\
VA size factor at high speed & - & 4 & 2 & 1.6 \\
VA size factor at low speed & - & 2 & 1.5 & 1.33 \\
Overall size factor & 1 & 4 & 2 & 1.6 \\
\hline
\end{tabular}

failure with the listed components leads to the failure of the entire system. For redundancy, the reliability of a fault-tolerant actuation system can be improved by using multi-lane setup. Failures per hour for a system with $\mathrm{n}$ lanes is $\lambda_{1}^{n}$ for a single lane failure per hour value of $\lambda_{1}$.

For multi-lane fault-tolerant drives capable of surviving failure of one lane, the remaining functioning lanes must be overrated to account for faulted operation [21]. Functioning lanes must be able to overcome the mean torque from the faulted lane in high-speed operation and exceed the mean drag torque from a lane with a shorted phase or phase set during low-speed operation. The respective per-lane sizing factors for different three phase multi-lane fault-tolerant topologies are shown in Table I.

\section{RESUlts}

The proposed sizing, design, and modelling procedure is applied to a case study of a electric drive system with a centralised topology with a nominal continuous power of $3 \mathrm{~kW}$, 9000RPM. The inverter and its output LC filter is located in the pressurised fuselage and is connected to the machine via a 50 metre long cable located on the wing. A triple-lane faulttolerant topology with a per-lane overrating size factor of 2 is selected. Thus, each lane's power output is $1 \mathrm{~kW}$ during nominal non-faulted operation, $2 \mathrm{~kW}$ during faulted and is overrated accordingly. All results presented are with respect to per-lane system under nominal non-faulted condition.

The per-lane system's total mass and total input power are $21.6 \mathrm{~kg}$ and $1.1 \mathrm{~kW}$ respectively as shown in Fig. 12. From this,
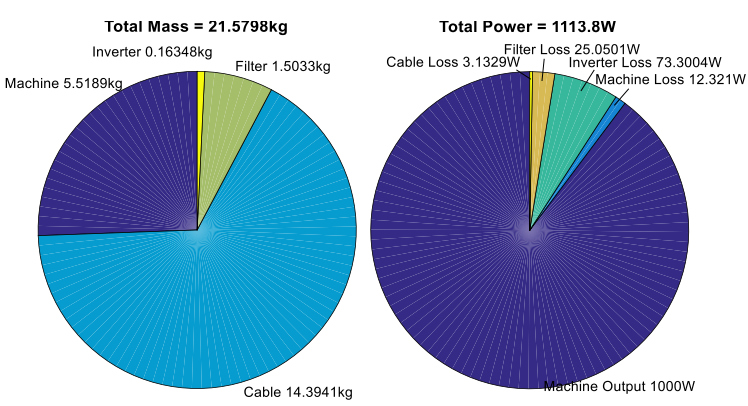

Fig. 12. Per-lane mass and power breakdown.
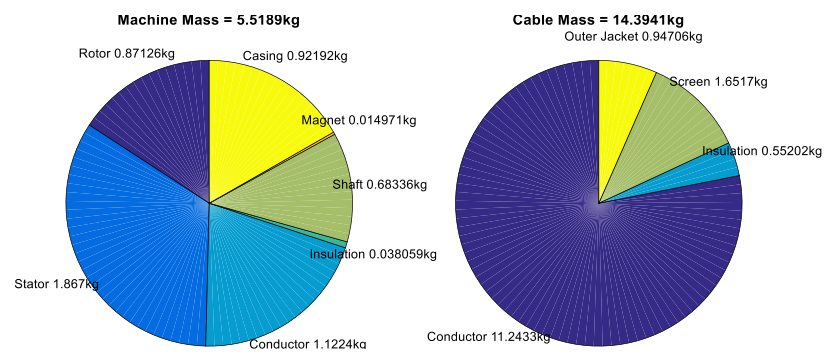

Fig. 13. Per-lane machine and cable mass breakdown.

the system efficiency can be calculated as $89.8 \%$. The majority of the system's mass is that of the $50 \mathrm{~m}$ long cable followed by the machine. The mass breakdown of these components are shown in Fig. 12. Over 75\% of the cable's mass consisting of the conductor.

The sized system is simulated in PLECs. The system is operating at steady state, the drive set to current control mode. The current operating point is set to generate a constant nominal torque with no flux weakening, i.e. $i_{q}=I_{p h} \sqrt{2}$ and $i_{d}=0$. The switching scheme used is space vector modulation. The cable model used is a distributed parameter transmission line model. The system values can be seen in Table II.

The filter and machine voltage and current waveforms are shown for nominal operating conditions in Fig. 14. Voltage values are with respect to ground. Filter inductor current is the same as the inverter output current because the inductor is connected in series with the inverter output. The designed peak-to-peak filter capacitor ripple current to peak-to-peak filter inductor current ratio $c_{C}$ is 0.1 and the corresponding

TABLE II

SySTEM VALUES.

\begin{tabular}{lc||lc}
\hline Slots/poles/phases & $24 / 4 / 3$ & Rotor diameter & $47.8 \mathrm{~mm}$ \\
\hline$V_{\mathrm{dc}}$ & $270 \mathrm{~V}$ & Stator diameter & $93.1 \mathrm{~mm}$ \\
\hline$f_{\mathrm{sw}}$ & $15 \mathrm{kHz}$ & Stack length & $78.1 \mathrm{~mm}$ \\
\hline$T_{\text {nom }}$ & $1.06 \mathrm{Nm}$ & $f_{\text {fil }}$ & $4.74 \mathrm{kHz}$ \\
\hline $\mathrm{RPM}$ & $9000 \mathrm{RPM}$ & $L_{\text {fil }}$ & $2.17 \mathrm{mH}$ \\
\hline$I_{\mathrm{ph}}$ & $8.4 \mathrm{Arms}$ & $C_{\text {fil }}$ & $518.53 \mathrm{pF}$ \\
\hline$J$ & $4.2 \mathrm{~A} / \mathrm{mm}^{2}$ & $R_{\mathrm{ac}}^{\prime}$ & $2.49 \mathrm{~m} \Omega / \mathrm{m}$ \\
\hline$R_{\mathrm{S}}$ & $25.57 \mathrm{~m} \Omega$ & $L^{\prime}$ & $326.7 \mathrm{nH} / \mathrm{m}$ \\
\hline$L_{\mathrm{s}}$ & $1.086 \mathrm{mH}$ & $C_{\mathrm{c}}^{\prime}$ & $43.3 \mathrm{pF} / \mathrm{m}$ \\
\hline$\lambda_{\mathrm{m}}$ & $0.0298 \mathrm{~Wb}$ & $C_{\mathrm{g}}$ & $126.1 \mathrm{pF} / \mathrm{m}$ \\
\hline
\end{tabular}



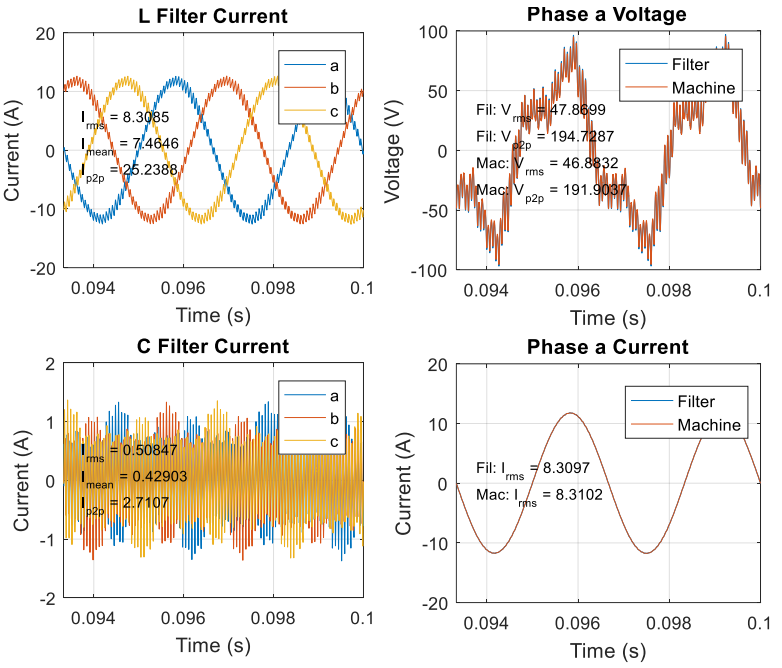

Fig. 14. Inverter, filter, and machine voltage and current waveforms.
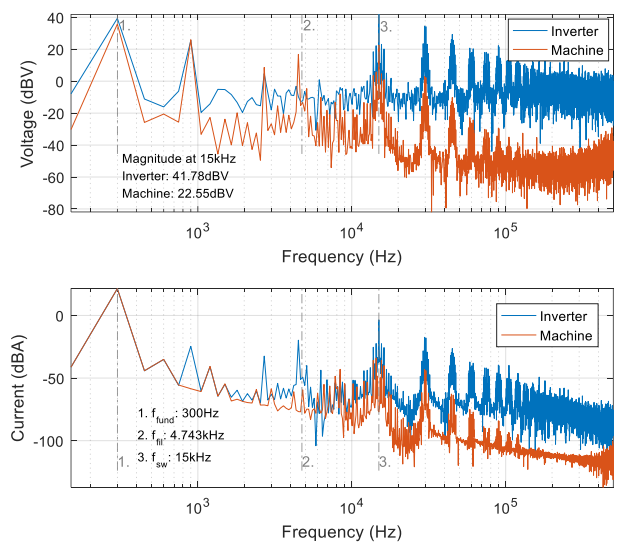

Fig. 15. Inverter and machine, voltage and current distortion spectrum.

simulated value is 0.13 . By comparing the phase "a" filter and machine voltages, no voltage overshoot is observed. The filter's and machine's peak-to-peak voltages are $194.73 \mathrm{~V}$ and 191.9V respectively. Filter and machine currents are smooth due to presence of the machine's stator inductance.

The inverter and machine voltage and current distortion spectrum can be seen in Fig. 15. The numbered vertical dashed lines mark the fundamental, filter cut-off, and switching frequencies. The desired harmonic attenuation at the $15 \mathrm{kHz}$ switching frequency is $-20 \mathrm{~dB}$. The filter frequency is determined as $4.743 \mathrm{kHz}$ using (49). The resultant attenuation of the simulated inverter voltage is $-19.23 \mathrm{dBV}$ at $15 \mathrm{kHz}$.

\section{CONCLUSION}

The aviation industry's desire for more electric aircraft is motivated by efficiency, fuel, maintenance, and weight saving with particular interest in the electrification of aerospace actuators. Unique challenges are associated with designing and operating reliable drive systems at high altitude, low pressure environments. A comprehensive system sizing procedure for aerospace electric drive systems with long-feeder cables has been presented. Sizing and design procedures for the machine, cable, filter, and inverter has been shown. The procedure was applied to a case study of a $3 \mathrm{~kW}$ 9000RPM drive system with a $50 \mathrm{~m}$ cable. A three-phase three-lane fault-tolerant topology is selected whereby each lane is overrated for single-lane fault conditions. The sized system is simulated in PLECs and the results are presented.

\section{REFERENCES}

[1] R. J. Kerkman, D. Leggate, and G. L. Skibinski, "Interaction of drive modulation and cable parameters on AC motor transients," IEEE Transactions on Industry Applications, vol. 33, no. 3, pp. 722-731, May 1997.

[2] R. S. Arajo, R. A. Rodrigues, H. de Paula, L. M. R. Baccarini, and A. V. Rocha, "Premature wear and recurring bearing failures in an inverter driven induction motor 2014; part I: Investigation of the problem," in 2013 IEEE Industry Applications Society Annual Meeting, Oct 2013, pp. $1-6$.

[3] T. J. E. Miller, Speeds electric motors: an outline of some of the theory in the SPEED software for electric machine design: with problems and solutions. Magna Physics, 2004.

[4] A. Boglietti, A. Cavagnino, and M. Lazzari, "Computational algorithms for induction-motor equivalent circuit parameter determinationpart I: resistances and leakage reactances," IEEE Transactions on Industrial Electronics, vol. 58, no. 9, pp. 3723-3733, Sep. 2011.

[5] J. Kirtley, "6.685 Electric Machines MIT OpenCourseWare," 2013. [Online]. Available: https://ocw.mit.edu/courses/electrical-engineeringand-computer-science/6-685-electric-machines-fall-2013/index.htm

[6] T. J. E. Miller, "Brushless permanent-magnet and reluctance motor drives," 1989.

[7] K. Venkatachalam, C. R. Sullivan, T. Abdallah, and H. Tacca, "Accurate prediction of ferrite core loss with nonsinusoidal waveforms using only steinmetz parameters," in 2002 IEEE Workshop on Computers in Power Electronics, 2002. Proceedings., June 2002, pp. 36-41.

[8] P. H. Mellor, D. Roberts, and D. R. Turner, "Lumped parameter thermal model for electrical machines of tefc design," IEE Proceedings $B$. Electric Power Applications, vol. 138, no. 5, pp. 205-218, Sep. 1991.

[9] Z. J. Liu, D. Howe, P. H. Mellor, and M. K. Jenkins, "Thermal analysis of permanent magnet machines," in 1993 Sixth International Conference on Electrical Machines and Drives (Conf. Publ. No. 376), Sep. 1993, pp. $359-364$.

[10] F. P. Incropera, A. S. Lavine, T. L. Bergman, and D. P. DeWitt, Fundamentals of heat and mass transfer. Wiley, 2007.

[11] C. W. T. McLyman, Transformer and inductor design handbook. CRC press, 2016.

[12] V. Valchev and A. Van den Bossche, "Accurate natural convection modelling for magnetic components," Microelectronics Reliability, vol. 43, no. 5, pp. 795-802, 2003.

[13] V. Roederstein, "Specification mkp1848 dc-link, revision 02 oct. 2012," 2014.

[14] S. AS50881, "Wiring aerospace vehicle," USA: SAE International, 2010.

[15] B. Standards, "BS 606604-4 insulation coordination for equipment within low-voltage systems - part 4: Consideration of high-frequency voltage stress," 2010.

[16] A. F. Moreira, T. A. Lipo, G. Venkataramanan, and S. Bernet, "Highfrequency modeling for cable and induction motor overvoltage studies in long cable drives," IEEE Transactions on Industry Applications, vol. 38, no. 5, pp. 1297-1306, Sep 2002.

[17] N. Idir, Y. Weens, and J. J. Franchaud, "Skin effect and dielectric loss models of power cables," IEEE Transactions on Dielectrics and Electrical Insulation, vol. 16, no. 1, pp. 147-154, February 2009.

[18] A. Wintrich, U. Nicolai, W. Tursky, and T. Reimann, Application manual power semiconductors. ISLE Verlag Ilmenau, 2011, vol. 7, no. 6.

[19] I. Mudawar, "Assessment of high-heat-flux thermal management schemes," IEEE Transactions on Components and Packaging Technologies, vol. 24, no. 2, pp. 122-141, 2001.

[20] FIDES group, "Reliability methodology for electronic systems," FIDES guide, 2009.

[21] J. Bennett, B. Mecrow, D. Atkinson, and G. Atkinson, "Safety-critical design of electromechanical actuation systems in commercial aircraft," IET Electric Power Applications, vol. 5, no. 1, pp. 37-47, 2011. 